\title{
Discriminación a la comunidad afrodescendiente en los bares Punto G, Lupe 83 y Kinky de Bogotá
}

Andrés Felipe MeZA

Carol Rodríguez GutiérreZ ${ }^{\text {I }}$

\section{Introducción}

La situación de discriminación a la comunidad afro en Colombia, se evidencia desde los aspectos laborales, sociales, culturales, políticos y religiosos. Dichas problemáticas aquejan a la sociedad victimaria, sin embargo una de ellas es la distinción que se hace en los bares de Colombia, como lo presentó el periódico El Tiempo en el año 2005 hubo un "revuelo en Cartagena por casos de discriminación en bares de la ciudad", realmente fue una verdadera polémica porque a la población afrocolombiana se le está negando la entrada a exclusivos sitios nocturnos por su color de piel.

En el ejercicio investigativo que se realizó se quiere apreciar una contextualización sobre la realidad que tienen que vivir las personas afros al momento de ser rechazadas y discriminadas en un bar. Durante la investigación analizaremos la participación e incidencia que los actores sociales seleccionados tienen en la problemática de investigación que hemos adoptado.

1 Estudiantes de la Facultad de Comunicación Social de la Universidad Santo Tomás. 
El estudio que tiene como objetivo dar cuenta de una realidad social para cuestionarla y evaluarla debe ser re-pensada desde los escenarios dónde estamos construyendo la cultura y el lenguaje, para dar cuenta de ello, por lo tanto Eduardo Restrepo (2011), el cual nos brinda los aportes de los estudios afro desde la rama de los estudios culturales:

Para los estudios culturales, la labor intelectual y la teoría importan no en sí mismas sino como un indispensable desvío hacia la intervención política. La labor intelectual y la teoría no solo constituyen y disputan concepciones del mundo, sino que también pueden convertirse en insumos para comprender más adecuadamente las relaciones sociales y las condiciones materiales en las que se re-produce nuestra existencia. (Restrepo, 2011)

Todo ello para un análisis crítico y bien elaborado en cual se propicien escenarios de discusión, diálogo y debate para la construcción de lo público y el bien común al hablar de cómo se presentan las exclusiones de la comunidad afrocolombiana, específicamente en los lugares exclusivos nocturnos de la cuidad de Bogotá.

Para tener más información de lo que está sucediendo en los bares, especialmente en de Punto G, Lupe 83 y Kinky de Bogotá, en los cuales se han conocido quejas de usuarios por tal problemática. Es necesario adquirir la documentación y noticias que se han reportado a lo largo del 2005 y 2015, además se hará uso de testimonios y encuestas para dar cuenta si ésta problemática se está controlando mediante el Estado.

La vulneración de Derechos Humanos a las comunidades afros es una problemática que afecta directa e indirectamente a gran parte de la sociedad colombiana, y es por esto que decidimos trabajar este aspecto de la vida real de la comunidad afro, ya que consideramos que es de vital importancia que los derechos fundamentales de dichas personas sean respetados, y que éstos sean tratados con igualdad.

Como primera medida, se toma como referencia un artículo de Hernando Salazar, del medio BBC Mundo de octubre 18 del 2008, denominado Discriminación por Raza en Bares de Bogotá en la cual plantea: 
Conocer la problemática que gira en torno a la discriminación racial en bares de Bogotá, y qué se está haciendo para prevenirla y erradicarla.

El autor busca dar a conocer la problemática y todas las implicaciones que traen este tipo de acciones e ir a las diferentes fuentes implicadas directa o indirectamente en el problema para poder desglosar la situación e identificar qué organismos e instituciones están a cargo de solventar esta situación y a través de qué planes o estrategias lo hacen.

Además existe la preocupación por saber qué garantías se establecen para las personas afros, a la hora de querer entrar a un establecimiento de este tipo sin ser discriminados. También saber la manera en cómo los propietarios de bares o sus miembros del staff ejercen el "derecho de admisión" y cómo este afecta directa o indirectamente a ambas partes. Y por último, qué instituciones velan porque se respete el derecho a la igualdad con eficacia (Salazar, 2008).

Seguido a esto, es importante mencionar que en Latinoamérica, se ha realizado un amplio número de proyectos investigativos en los que se abordan las problemáticas de las comunidades afro, sin embargo el tema de la exclusión en bares no ha sido tan estudiado e indagado como sí al de sectores laborales, políticos y culturales.

Sin embargo, a la comunidad afrocolombiana en 1992 le asignaron la garantía de derechos de igualdad como se contempla en el Reglamentado por el Decreto 306 de 1992 en el cual se descubre que:

El derecho a la igualdad de personas afrodescendientes Discriminación por origen racial como un "criterio sospechoso" es inadmisible por el orden constitucional y la comunidad internacional, castiga con indemnización a dicha persona como lo establece el Decreto 2591 de 1991, articulo 25: Indemnizaciones y costas. Cuando el afectado no disponga de otro medio judicial, y la violación del derecho sea manifiesta y consecuencia de una acción clara e indiscutiblemente arbitraria, además de lo dispuesto en los dos artículos anteriores, en el fallo que conceda la tutela el juez, de oficio, tiene la potestad de ordenar en abstracto la indemnización del daño emergente causado si ello fuere necesario 
para asegurar el goce efectivo del derecho así como el pago de las costas del proceso. (Reglamentado por el Decreto 306 de 1992)

A raíz de ello se quiere dar cuenta que tanto se cumple esa ley, en cuanto a la selección de los actores sociales, consideramos que serán los que hayan vivido dicha discriminación, propietarios de establecimientos y funcionarios encargados de los DD.HH. de la comunidad afro pues son éstos los que tienen una relación directa con la problemática que trataremos, y por ende son nuestra mayor fuente de información en nuestra investigación.

La reconstrucción social plantea el papel activo de los actores sociales y su rol en la sociedad, con el objetivo de reivindicar un significado ideológico, detectando el retroceso de la problemática con la observación clara y crítica de su historia (Aquine. C., 2010), el problema que se le critica a esta lección es que es demasiado general; sin embargo será útil pero sin caer en la generalización.

Empleando como fuente el libro de Rosana Guber (2001), La etnografía: Método, campo y reflexividad utilizaremos de allí algunos instrumentos metodológicos que nos servirán para nuestro trabajo, se iniciará con un desplazamiento a la zona T de Bogotá, con el objetivo de acercarnos a las fuentes confiables analizando la indexicalidad de todas las personas que nos brinden testimonios, para no presuponer la existencia de significados y abolir la subjetividad (esto lo abordaremos mediante la Descripción densa propuesta por Geertz (1991), y la reflexividad se construirá una realidad crítica, con inmediatez de comprensión, racionalidad y una visión social con auge de cambio. Debido a que seremos voluntarios investigativos, la observación participante nos será una herramienta importante a la hora de analizar la vulneración de Derechos Humanos y la discriminación de personas afros. Todo lo anterior nos permite abordar una serie de herramientas que va a arrojar una investigación cualitativa clara y consistente. Para lograr la misma optamos por recursos como entrevistas, registros escritos y audiovisuales, visitas a los espacios, notas de campo, diálogos teóricos, entre otros y se entablaran conclusiones encaminadas a la resolución de la pregunta y a la problemática. Todo con el fin de darle una posible respuesta a nuestra hipótesis inicial que es ¿de qué 
manera los bares de Punto G, Lupe 83 y Kinky de Bogotá ejercen, el derecho de admisión' contribuyendo a la discriminación de las personas afros y cómo el Estado sanciona estas prácticas velando por los Derechos Humanos de dicha comunidad?

\section{Análisis de práctica en los bares de la cuidad de Bogotá}

A partir de la experiencia vivida con Andrea Solís, realizamos la investigación e inmersión para esclarecer de qué manera es su trato con una persona afro los bares Punto G, Lupe 83 y Kinky en la zona rosa - norte de Bogotá.

El experimento consistía en ir a dichos bares, con la posibilidad de pagar cover, consumo y hacer fila. Eran 3 mujeres blancas y Andrea, una joven de 24 años de edad, bien vestida y afro.

Se inició en Punto G, hicieron fila por 5 minutos aproximadamente y una chica de logística le dijo que el cover era de \$20.000, sin embargo recibió una notificación por su radio donde se escuchaba claramente que "el bar está lleno y no había disponibilidad para ingresos hasta nueva orden", se fueron y 3 minutos después pasaron nuevamente por la zona y en el lugar estaba entrando personas.

El segundo lugar Lupe 83, estaba lleno, desde afuera se notaba pero después de hacer fila, de pagar cover de $\$ 20.000$ y de que notificaran si eran aptas o no la respuesta en el radio fue un sí, se le preguntó a la joven de logística en que se basaban para el derecho de admisión y su respuesta fue: en el vestuario.

El último lugar era Kinky, en este las cosas parecían un poco más difíciles el cover era de $\$ 30.000$ y con requisa, fila de 10 minutos se logró entrar.

El experimento solo constató que en un bar posiblemente si se discrimine la comunidad afro pues Punto G siguió operando toda la noche con total normalidad.

Esto nos permite dar una respuesta a nuestra pregunta, en la cual sí se evidenció una discriminación en uno de los bares, quizá en los otros no se vivió la situación porque ya el Estado sí pone a regir la ley 
de indemnización, como se conoció en el caso de discriminación a las hermanas Acosta en Cartagena:

[...] después de presentado el incidente discriminatorio en las discotecas, Johana Acosta interpuso acción de tutela para invocar el derecho a la igualdad... La tutela fue seleccionada para revisión por la Corte Constitucional, que revocó todas las actuaciones anteriores y le dio la razón al Juzgado Octavo Civil Municipal, que condenaba a la discoteca a indemnizar a las afectadas. (El Universal, 2011)

Por otra parte, es indispensable que se utilice un lenguaje cuidadoso e inclusivo cuando se refiera a la comunidad afro, pues lo que se procura a partir de estos análisis, es generar un cambio en la manera de nombrarlos, de tal forma que el discurso utilizado sea inclusivo y se promulgue la igualdad y la equidad en la implementación de un discurso equitativo que se vea reflejado en todos los productos comunicativos, "si la historia del negro en Colombia está sujeta a la visión colonial, representada a través de la esclavización, es lógico suponer que las construcciones simbólicas de representación de la comunidad negra aparezcan como una proyección del pasado colonial" (Jaramillo, 2011). Lo que impide que la población en cuestión, deje ser tratada como una minoría y su cultura, hábitos y costumbres, se degraden por su condición ancestral.

Posteriormente de todo lo nombrado, se hace una leve comparación con el libro Galaxia Gutenberg del autor Marshall McLuhan, el cual presenta en su capítulo "El conocimiento del alfabeto afecta tanto la fisiología como la vida psíquica del africano" una postura crítica basada en autores que han estudiado el tema, en el cual postula que Carothers considera que es "notablemente, rápido y trascendente los cambios que una educación ha producido en los niños y niñas africanos, hasta el punto de que en una sola generación las características y reacciones humanas han variado como cabía esperar ocurriese en el transcurso de varios siglos" (Carothers en McLuhan, p. 318).

Así mismo se considera en el capítulo que las cualidades de la comunidad afro, especialmente en los africanos, son influencias en 
la educación de los mismas, la cultura y su lenguaje han aportado a una estigmatización la cual se refleja en los diversos casos de racismo o discriminación a la comunidad afro en establecimientos públicos, acotando la intervención y visibilización de dicha problemática en los medios de comunicación, que en ocasiones se observa que solo hay denuncias en ciudades donde la comunidad afro es abundante como Cartagena en el cual el diario El Universal sigue la investigación del caso de discriminación nombrado anteriormente; la comunidad a raíz de las costumbres y sus ideologías en primera instancia tiene derechos y se contempla la idea una mentalidad diferente en la cual se puedan manifestar las actitudes, los antepasados, la cultura, los hábitos, la educación y centenares de características de la comunidad afrodescendiente. Al fin y al cabo es de vital importancia la reflexión que deja el autor del libro, en el cual considera que

la nueva generación es distinta por completo, capaz de elevarse a mayor altura y de caer más hondo, merecen una mayor comprensión de sus dificultades y de sus tentaciones muchos mayores. Antes que sea demasiado tarde es preciso enseñar esto a los padres africanos, para que puedan darse cuenta de que los hijos con que han de habérselas son mecanismos más delicados que ellos lo fueron. (McLuhan, 1962)

Finalmente se hace alusión al artículo 13 de la Constitución Política de Colombia de 1991, el cual cobija a todas las comunidades minoritarias, en el cual se expresa la garantía que debe ofrecer el Estado, para que se respete el derecho a la igualdad y libertad a toda la población colombiana:

Todas las personas nacen libres e iguales ante la ley, recibirán la misma protección y trato de las autoridades y gozarán de los mismos derechos, libertades y oportunidades sin ninguna discriminación por razones de sexo, raza, origen nacional o familiar, lengua, religión, opinión política o filosófica. El Estado promoverá las condiciones para que la igualdad sea real y efectiva y adoptará medidas en favor de grupos discriminados o marginados. 


\section{Referencias}

Álvarez. R (2011) El Universal, 28 de mayo de 2011

Aquine, C. (2010). Reconstrucción social.

Guber, R. (2001). La etnografía: Método, campo y reflexividad. Capitulo III: Observación participante. Norma.

Geertz, C. (1991). La Interpretación de las Culturas. Capítulo I: Descripción Densa: Hacia una Teoría Interpretativa de la Cultura. México.

Jaramillo, J. I. (2011). "Mestizos outsiders, negros desaparecidos en las crónicas del Río de la Plata en los siglos xv y xvı", en Revista Comunicación y Ciudadanía Número 4, Facultad de Comunicación Social. Bogotá: Universidad Externado de Colombia.

McLuhan, M (1962). Galaxia Gutenberg. Cap. "El conocimiento del alfabeto afecta tanto la fisiología como la vida psíquica del africano”. Páginas $22-24$.

Restrepo, E. (2011). Estudios afrolatinoamericanos: posibles aportes desde los estudios culturales. Tomado de: http://www.ram-wan.net/restrepo/ documentos/estudios $\% 20$ afroamericanos $\% 20$ posibles $\% 20$ aportes $\% 20$ desde $\% 20$ eeccs.pdf

Salazar, H . (2008). Discriminación por raza en bares de Bogotá. Revista Semana BBC Mundo. 